\title{
Finding, defining and breaking the diffraction barrier in microscopy - a historical perspective
}

\author{
Marcel A Lauterbach
}

\begin{abstract}
Diffraction plays a crucial role in microscopy as it prevents the recording of arbitrarily sharp images with conventional light microscopes. Many names are connected with the notion of diffraction and the definition of resolution. An overview over the contributions of the different scientists to the recognition and definition of the diffraction barrier in the past centuries is given and the recent developments that led to breaking this barrier are portrayed.
\end{abstract}

Keywords: History, Diffraction limit, Diffraction barrier, Abbe formula, Resolution, High-resolution microscopy, Fluorescence, STED, PALM, STORM

\section{Recognizing the diffraction limit}

It was long believed that spatial resolution of light microscopes is ultimately limited by diffraction. Ernst Abbe is perhaps the one who is most often cited for the notion that the resolution in microscopes would always be limited to half the wavelength of blue light, because he stated it saliently. But also many others were aware of the resolution limitation due to diffraction and contributed to its understanding.

The limiting role of diffraction for microscopy is extensively discussed in the famous work by Ernst Abbe in 1873 (Abbe 1873). Here, the resolution limit for microscopic images of half the wavelength (of blue light) is explicitly stated for the first time ${ }^{\mathrm{a}}$.

Abbe considers therefore replacing the eye by a detector that is sensitive to even shorter wavelengths - at his time photographic plates - to increase resolution ${ }^{\mathrm{b}}$.

Abbe describes in words also his famous formula:

$$
d_{\min }=\lambda /[2 \sin (\alpha)]
$$

where $d_{\min }$ is the minimal resolvable distance, $\lambda$ the wavelength of the light, and $\alpha$ the half aperture angle of the microscope's objective ${ }^{\mathrm{c}}$; it is left open whether $\lambda$ refers to the wavelength in the immersion medium or in air. Abbe does not discuss explicitly the influence of the refractive

Correspondence: Marcel.Lauterbach@parisdescartes.fr Wavefront Engineering Microscopy Group, Neurophysiology and New Microscopies Laboratory, CNRS UMR8154, INSERM S603, University Paris Descartes, Sorbonne Paris Cité, Paris, France index in the sample and the immersion medium, though he does consider immersion objectives.

It is interesting to note that Abbe's 56-page article does not contain any formula in mathematical notation. Abbe sees the microscopic object as consisting of diffraction gratings. The object diffracts the illuminating light and only if a sufficient number of diffraction orders passes the finite-sized objective, the object can be resolved. As becomes apparent in a later article (Abbe 1880), he did therefore not recognize that the same resolution limits also apply to self-luminous objects ${ }^{\mathrm{d}}$ (as used in fluorescence microscopy, which was developed much later). Nevertheless, in his article from 1873 (Abbe 1873), he already acknowledges the possibility of new developments that are not covered by his theory and that might enhance the possibilities of optical microscopes beyond the limits that he derived ${ }^{\mathrm{e}}$.

Only one year after Abbe's first article about the resolution limit (Abbe 1873) appeared, Hermann von Helmholtz published the same results ${ }^{\mathrm{f}}$ (von Helmholtz 1874). In contrast to Abbe, von Helmholtz gives a detailed mathematical derivation of his findings. In the last paragraph of his article he states that he had finished his work before he became aware of Abbe's publication and that it seems acceptable for him to publish his findings in addition to Abbe's work for they contained the mathematical proofs, which were missing in Abbe's article.

In addition, von Helmholtz tries to illuminate the object in a way that avoids phase relations at different object points (i. e. incoherently) by imaging the light source onto the object. From his theory he concludes that diffraction

\section{是 Springer}

(C) 2012 Lauterbach; licensee Springer. This is an Open Access article distributed under the terms of the Creative Commons Attribution License (http://creativecommons.org/licenses/by/2.0), which permits unrestricted use, distribution, and reproduction in any medium, provided the original work is properly cited. 
effects should then vanish. He denotes the persistence of diffraction to the remaining phase relationships in the object plane. Like Abbe he does not recognize that diffraction effects would remain even with self-luminous objects and would hence limit the resolution.

Although the articles from Abbe and von Helmholtz are the first ones dealing in detail with the resolution limitations of microscopes, the effects of diffraction and its implication for resolution were known earlier. In 1869 Émile Verdet (1869) seems to be one of the first who explicitly mention that microscopes are limited in their resolution by diffraction ${ }^{\mathrm{g}, \mathrm{h}}$.

He uses a slightly different separation criterion and arrives at similar results for resolution as later Abbe and von Helmholtz, which he derives for the case of telescopes (i. e. in terms of viewing angle and aperture diameter). He finds that for circular apertures $\sin \omega=0.819 \lambda / R$, where $\omega$ denotes the viewing angle of the first bright ring, $\lambda$ the wavelength of the light used and $R$ the radius of the aperture. He considers $1 /(2 \omega)$ as the resolution limit.

Detailed experimental tests of Abbe's theory including the demonstration of artifacts in the microscopic images are published by J. W. Stephenson in 1877 (Stephenson 1877).

Some years later, in 1896, Lord Rayleigh (1896) discusses extensively the resolution of microscopes. He is the first to deal with illuminated objects as well as with self-luminous objects. He also distinguishes between different phase relationships of the illuminated objects. Lord Rayleigh extends his investigations to different objects (points, lines, gratings) and different aperture shapes. He emphasizes the similarities of microscopes and telescopes and complains about insufficient communication between physicists and microscopists ${ }^{i}$. Already in 1872, he deals - still under his former name J. W. Strutt - with the diffraction in telescopes and extends known results to annular apertures (Strutt 1872), being unaware of an earlier publication by Airy (1841), which also deals with diffraction at annular apertures, as he states in a post scriptum. In 1874 Lord Rayleigh investigates the resolution - also in terms of the "Rayleigh criterion" imaging gratings (Rayleigh 1874). Here, he states that the theoretical resolution cannot be obtained for large areas due to imperfections (spherical and chromatic aberrations) of the available lenses but that it would be possible with microscope objectives ${ }^{\mathrm{k}}$.

It is Airy in 1835 (Airy 1835) who calculates for the first time the diffraction image of a point source when the limiting aperture is circular in shape. As an example, he states a star seen through a good telescope. Apparently, Airy considers the case of other aperture shapes so well known that he only states that the calculation of their diffraction patterns is never difficult but does not give further references ${ }^{1}$. Airy does not explicitly state that the diffraction limits resolution (i. e. the possibility to separate different stars), but it can be assumed that he was aware of this fact.

Later, in 1867, W. R. Dawes (1867) addresses the problem of separating double stars. From his observations he derives empirically that the angular separating power scales as $4^{\prime \prime} .56 / a$, where $a$ is the aperture size in inches. He points out that he had found by observation the inverse scaling of diameters of star-disks with aperture diameter about 35 years ago ${ }^{\mathrm{m}}$. He, too, does not mention the earlier work of Airy.

As will be shown below, ways to shift, circumvent and break the diffraction limit were found later.

Recognizing that broadening of imaged structures is inevitable due to diffraction is the first step in understanding the resolution of microscopes. The second step is the finding of criteria to define a structure as "resolved". These criteria will be discussed in the following section.

\section{Resolution criteria}

The key figure of merit of an optical system is its resolution, i. e. its ability to ascertain an unknown number of objects or details that give identical signal as distinct entities. Resolution must not be confused with localization precision, the ability to determine the exact position of an object.

Different notions are possible, when two objects should be regarded as resolved (den Dekker and van den Bos 1997; Ramsay et al. 1941). This is especially critical when instruments with different PSF (point spread function) shapes are compared. A common choice is the Rayleigh criterion, which was published in 1874 (Rayleigh 1874). Lord Rayleigh regards a structure resolved if the principal intensity maximum of one diffraction pattern coincides with the first minimum of the neighboring diffraction pattern. His choice is made in a time when the human eye, which cannot resolve arbitrarily small intensity differences, is the common photodetector.

Schuster states in 1904 that there is something arbitrary in the Rayleigh criterion as the dip in intensity necessary to indicate resolution is a physiological phenomenon (i. e. depends on the ability of the observer's eye to perceive a weak intensity dip) (Schuster 1904). According to him, two point sources should only be called resolved, if no portion of the main lobe of one diffraction pattern overlaps with the main lobe of the other. This doubles Rayleigh's distance.

Sparrow asserts in 1916 with its "undulation condition" (Sparrow 1916) as the resolution limit the distance between point objects for which the second derivative of the composite intensity distribution at the center of the image just vanishes. This is the ultimate limit for photodetectors (replacing the naked eye) that can resolve arbitrary small intensity differences. 
Houston proposes in 1927 to use the FWHM (full width at half maximum) of the PSF to quantify resolution (Houston 1927). Houston's limit is widely used, because it is - in contrast to the Rayleigh criterion - also applicable to diffraction patterns that do not fall off to zero, as in the case of a Gaussian or Lorentzian profile.

Buxton regards in 1937 two point objects as resolved, if the diffraction patterns intersect at their inflection points (Buxton 1937).

All of these criteria assume noise-less images. Quantifying resolution becomes more complex, if noise and not only incoherent (as in fluorescence microscopy) but also coherent or partially coherent sources are considered (den Dekker and van den Bos 1997).

\section{Shifting the diffraction limit}

As stated above, Abbe's diffraction limit amounts for the shortest wavelength of visible light to about $200 \mathrm{~nm}$ for the lateral resolution. Smaller details cannot be resolved. The axial resolution is even worse, typically by a factor of three to four.

A multitude of methods was therefore developed to surpass the resolution limit in light microscopy [For reviews see e.g. (Heintzmann and Gustafsson 2009; Hell 2007, 2009; Huang et al. 2010; Ji et al. 2008; Lippincott-Schwartz and Manley 2009; Rice 2007)]:

First, methods to shift or circumvent the diffraction limit were contrived:

Apodizing (di Francia 1952) can sharpen the central maximum, but leads to large side lobes, which render the method impractical (Hell 2007), since for obtaining a smaller and smaller central maximum an increasing fraction of the total available light flux is redirected to the side lobes (di Francia 1952).

The optical near field is used for recovering high spatial frequencies, thus resolving fine details, in scanning probe techniques as SNOM (Scanning Near Field Optical Microscopy) (Ash and Nicholls 1972; Pohl et al. 1984; Synge 1928) and TERS (Tip-Enhanced Raman Spectroscopy) (Anderson 2000; Hayazawa et al. 2000; Kawata et al. 2009; Stöckle et al. 2000); however, these techniques rely strictly on the close proximity of a probe to the sample. They are therefore limited to the imaging of surfaces.

TIRF (Total Internal Reflection) microscopy (Axelrod 1981; Temple 1981) illuminates only a very thin layer of the sample that is adjacent to the cover slip via an evanescent field of light. This enables depth discrimination and background suppression but does not ameliorate resolution: the method does not allow an enhanced optical separation of several alike objects. In addition, it remains limited to imaging structures in the vicinity of the cover slip.
In a confocal microscope (Minsky 1961), the sample is scanned with a focused beam of light. The fluorescence is recorded with a detector behind a pinhole. The pinhole rejects the out of focus light thereby enabling axial sectioning. The lateral resolution can be increased by up to a factor $\approx 1.4$ (Gustafsson 1999) under ideal conditions.

4Pi-microscopy (Hell and Stelzer 1992; Hell et al. 1994) and $\mathrm{I}^{2} \mathrm{M}$ (Image Interference Microscopy) (Gustafsson et al. 1995, 1996) increase the effective total aperture by the use of two opposing objectives, thereby enhancing the axial resolution.

Various kinds of structured illumination microscopy (Gustafsson 1999), sometimes combined with TIRF (Cragg and So 2000; Kner et al. 2009) or with the twolens approach, including $\mathrm{I}^{3} \mathrm{M}$ (Incoherent Interference Illumination Microscopy) (Gustafsson et al. 1995, 1996), $\mathrm{I}^{5} \mathrm{M}$ (the combination of $\mathrm{I}^{2} \mathrm{M}$ and $\mathrm{I}^{3} \mathrm{M}$ ) (Gustafsson et al. 1999), $\mathrm{I}^{5} \mathrm{~S}$ (a combination of $\mathrm{I}^{5} \mathrm{M}$ with laterally structured illumination) (Shao et al. 2008), SWFM (Standing Wave Fluorescence Microscopy) (Bailey et al. 1993) and HELM (Harmonic Excitation Light Microscopy) (Frohn et al. 2000) use non-uniform illumination of the specimen to extract high spatial frequencies. Spatial or temporal modulation of point illumination in SPIN (Scanning Patterned Illumination) or SPADE (Scanning Patterned Detection) microscopy ( $\mathrm{Lu}$ et al. 2009) would enable generalized structured illumination schemes with two-photon excitation (Denk et al. 1990) or spontaneous Raman scattering (Lu et al. 2009). ISM (Image Scanning Microscopy) (Müller and Enderlein 2010) uses point scanning in combination with descanned wide field detection.

These methods lead to extended resolution microscopy (Gustafsson 1999), but not to unlimited resolution microscopy in the far field. The diffraction limit is not fundamentally broken by any of these methods. In all of the far-field methods, the attainable resolution is limited to a finite value. They reach a new limit, which is on the order of a factor of two below Abbe's value, but they cannot provide a theoretically unlimited resolution.

Alternatively, one can abandon the advantageous visible light altogether. Reduction of the wavelength used for imaging is pursued in UV (Ultra Violet) (Abbe 1873; Brand et al. 1997) and X-ray microscopy (Kirz et al. 1995; Miao et al. 2008). Electron microscopy (Ruska 1934; von Borries and Ruska 1939) provides resolution up to the Angstrom regime (Ruska 1993), using electrons with a very short de Broglie wavelength for imaging. Only thin samples or surfaces of thick samples can be imaged and the specimen is placed in vacuum during imaging. Electron microscopy can be combined with optical fluorescence microscopy for profiting from the advantages of both techniques (Cortese et al. 2009). Scanning probe techniques such as AFM (Atomic Force Microscopy) (Binnig et al. 1986), STM (Scanning Tunneling Microscopy) (Binnig and Rohrer 
1983) and SICM (Scanning Ion-Conductance Microscopy) (Hansma et al. 1989) are restricted to imaging surfaces, but some can reach molecular resolution on biological samples (Müller et al. 2009).

\section{Breaking the diffraction limit}

More than a century after Abbe's seminal article was published, the diffraction limit in light microscopy has been broken by exploiting discernible states of markers and not only the electromagnetic field of the light: STED (Stimulated Emission Depletion) microscopy (Hell and Wichmann 1994) and other RESOLFT (Reversibly Saturable/Switchable Optical [Fluorescence] Transitions) techniques (Hell 2004; Hell and Kroug 1995; Hofmann et al. 2005) provide in theory a resolution without any optical limit.

After its theoretical description in 1994 (Hell and Wichmann 1994), STED microscopy was experimentally demonstrated in 1999 (Klar and Hell 1999). It restricts fluorescence to sub-diffraction regions at known positions by switching fluorescent markers to a non-signaling state by stimulated emission. A non-homogeneous light pattern with at least one close-to-zero-intensity point is scanned over the sample [For details on STED microscopy see e. g. (Hell 2007)].

A resolution better than $6 \mathrm{~nm}$ (Rittweger et al. 2009a) has been reached. Fast imaging (Westphal et al. 2007) with frame rates as high as 200 images per second (Lauterbach et al. 2010) has been demonstrated.

In RESOLFT microscopy general reversible saturable/ switchable optical (fluorescence) transitions are used for confining one of several marker states to a subdiffraction region. As in STED microscopy the position of the distinct marker states is predetermined by scanning a non-homogeneous light pattern over the sample. RESOLFT microscopy found manifold implementations, even though STED microscopy remains its most prominent form: GSD (Ground State Depletion) is a RESOLFT concept which uses the population of metastable states (e.g. triplet states) of the fluorophores to confine the region in which fluorescence is possible. After publication of the concept in 1995 (Dose 2009; Hell and Kroug 1995) it was successfully implemented in 2007 (Bretschneider et al. 2007). It provides a resolution below $8 \mathrm{~nm}$ (Rittweger et al. 2009b). Other implementations of the RESOLFT concept are (Hell 2007) SPEM (Saturated Patterned Excitation Microscopy) (Heintzmann et al. 2002) and SSIM (Saturated Structured-Illumination Microscopy) (Gustafsson 2005); however, in contrast to STED and GSD microscopy, mathematical postprocessing is required (Rittweger et al. 2009b). A similar method uses temporally modulated illumination and Fourier analysis to extract high frequency components resulting from saturation effects (Fujita et al. 2007). A special form of RESOLFT microscopy is DSOM (Dynamic Saturation Optical Microscopy) (Enderlein 2005), which makes explicit use of the fluorescence dynamics. Switchable fluorescent proteins (Hofmann et al. 2005; Schwentker et al. 2007) as well as switchable organic dyes (Bossi et al. 2006) were used for RESOLFT microscopy.

In 2006, closely related variants of another elegant approach to use the switching of states for high-resolution imaging emerged, named PALM (Photoactivation Localization Microscopy) (Betzig et al. 2006), STORM (Stochastic Optical Reconstruction Microscopy) (Rust et al. 2006; Zhuang 2009) and FPALM (Fluorescence Photoactivation Localization Microscopy) (Hess et al. 2006). Many more names followed as the stochastic principle was exploited in various facets and enhancements (Patterson et al. 2010). In these methods single molecules are switched individually (Dickson et al. 1997) and stochastically in space and are imaged onto a camera. Only a very small subpopulation of all marker molecules is kept simultaneously in the bright state at stochastically distributed positions. On average, at most one molecule per diffraction limited area must be in the bright state. In contrast to the above discussed scanning methods (STED microscopy, RESOLFT microscopy), the position of the fluorescence emission is not known a priori. It has to be found by localizing the origin of the fluorescence emission, as in earlier localization concepts of few alike objects (Gordon et al. 2004; Lidke et al. 2005; Qu et al. 2004). The molecules can be localized with high precision (Heisenberg 1930; Winick 1986; Thompson et al. 2002) if their diffraction patterns do not overlap. A new subset of molecules is subsequently switched on and their positions are determined from a new image. After numerous repeats of this cycle, a highresolution image can be reconstructed from the molecular positions, which were determined from non-overlapping diffraction patterns.

In common with the above described scanning methods, switching of the marker molecules into discernible states is used to separate images of individual details in time that cannot be separated forthrightly in space. In both cases a molecular mechanism makes sure that some of the marker molecules within the diffraction zone cannot contribute to the (fluorescence) signal, thus enabling a time sequential separation from those that can. Whereas both methods use the same switching principle, in the scanning methods the position where this switching is going to take place is predetermined $a$ priori by the positioning of the scanner; in the stochastic methods this position is found a posteriori by localization.

\section{Summary}

An overview was given over the contributions of many scientists who advanced in the $19^{\text {th }}$ and $20^{\text {th }}$ century 
the understanding of the limiting role of diffraction and the definition of resolution. Several techniques had been invented to enhance the resolution of optical far-field microscopes. They all remained bound to double the resolution in the best case. Finally, at the end of the $20^{\text {th }}$ century, scientists broke the diffraction barrier in optical microscopy by vigorously using the intrinsic marker properties instead of relying only on bent rays of light. The theoretical limit on optical resolution has thus been abandoned since states of markers have been recognized as the decisive new entities (Abbe 1873) surpassing Abbe's classical theory.

\section{Endnotes}

a" [...], so folgt, dass, wie auch das Mikroskop in Bezug auf die förderliche Vergrösserung noch weiter vervollkommnet werden möchte, die Unterscheidungsgrenze für centrale Beleuchtung doch niemals über den Betrag der ganzen, und für äusserste schiefe Beleuchtung niemals über den der halben Wellenlänge des blauen Lichts um ein Nennenswerthes hinausgehen wird." - [...], it follows that, however no matter how the microscope may be optimized with respect to the useful magnification, the possibility of discrimination for central illumination will never exceed noteworthily one wavelength and for extremely grazing illumination never half a wavelength of blue light. [Translations of non-English excerpts provided by the author.]

b“Nur bei photographischer Aufnahme der mikroskopischen Bilder kann die Unterscheidung noch merklich weiter reichen. Denn wegen der bedeutend kürzeren Wellenlänge der chemisch wirksamen Strahlen werden bei jedem Objectiv die Bedingungen für die photographische Abbildung sehr viel günstiger; nämlich so, wie sie für das directe Sehen eine im Verhältnis von $3: 2$ gröbere Structur stellen würde." - Only for photographic recording of the microscopic images the distinction can reach noticeably beyond [this limit]. Because of the considerably shorter wavelength of the chemically active rays the conditions become much better for photographic imaging, whatever objective is used; namely as a structure that is coarser by a ratio $3: 2$ would provide them.

c"Irgend eine bestimmte Farbe zu Grunde gelegt, ergiebt sich der betreffende Minimalwerth [der Auflösung] für rein centrale Beleuchtung durch Division der Wellenlänge mit dem Sinus des halben Oeffnungswinkels, für den höchsten zulässigen Grad schiefer Beleuchtung aber bei jedem Oeffnungswinkel genau halb so gross [...]" Given any well-defined color, the according minimal value [of resolution] for central illumination is given by the wavelength divided by the sine of the half aperture angle, but for the highest acceptable degree of grazing incidence for every aperture angle it is exactly half this value [...].

d“[...] diese Theorie soll sich ausgesprochenermassen auf die Abbildung solcher Objecte beziehen, bei welchen Beugung des Lichts in thesi statt findet; und sie behauptet ja ausdrücklich, dass derartige Objecte in anderer Weise, und nach anderen Gesetzen abgebildet werden als solche, bei denen keine Beugung in's Spiel kommt. Dass es nun Objecte der letzteren Art wirklich giebt, wie auf alle Fälle doch die selbstleuchtenden Körper, [...] beschränkt allerdings das Gebiet der Anwendung meiner Theorie, obwohl diese Beschränkung für die Mikroskopie praktisch gleichgiltig bleibt, so lange es keine mikroskopischen Glühwürmchen giebt [...]." - [...] this theory refers specifically to the imaging of such objects where diffraction occurs; and it states explicitly that such objects are imaged in a different way and with other laws, than objects for which diffraction plays no role. The fact that objects of the latter kind exist, as for sure the self-luminous bodies, [...] limits the applicability of my theory, although this limitation remains without importance for the microscopy as long as there are no microscopic fireflies [...].

e"Die eigentliche Capacität des Mikroskops im strengeren Sinne aber muss ich - so lange nicht Momente geltend gemacht werden, die ganz ausserhalb der Tragweite der aufgestellten Theorie liegen - schon bei der oben bezeichneten früheren Grenze als vollständig erschöpft ansehen." - I must regard the actual capability of the microscope in the rigorous sense as completely exhausted with the above described limit - as long as no entities are claimed that are out of reach of the derived theory.

f“Es sei die Grösse der kleinsten wahrnehmbaren Dis$\operatorname{tanz} \epsilon$, die der Wellenlänge im Medium des Objects $\lambda$, der Divergenzwinkel der einfallenden Strahlen ebenda $\alpha$, und $\lambda_{0}, \alpha_{0}$ seien die Werthe der letztgenannten Grössen für Luft. Dann ist nach den weiter unten abgeleiteten Formeln $\epsilon=\frac{\lambda}{2 \sin \alpha}=\frac{\lambda_{0}}{2 \sin \alpha_{0}} . "-B e$ the size of the minimum discernible distance $\epsilon$, the size of the wavelength in the medium of the object $\lambda$, the angle of divergence of the incoming rays therein $\alpha$, and $\lambda_{0}$, $\alpha_{0}$ be the values of the last-mentioned parameters in air. Then it is according to the later derived formulas: $\epsilon=\frac{\lambda}{2 \sin \alpha}=\frac{\lambda_{0}}{2 \sin \alpha_{0}}$.

g"Le travail des miroirs employés dans les télescopes est aujourd'hui si parfait, les verres des lunettes et des microscopes sont si heureusement combinés, que les aberrations qui résultent des lois de l'optique géométrique peuvent être presque entièrement évitées. Il semble donc que les rayons partis d'un point lumineux doivent, dans ces instruments, converger rigoureusement en un même point; cependant il n'en est rien, car dans les 
meilleurs télescopes l'image d'une étoile conserve un diamètre apparent sensible. La théorie que nous venons d'exposer fournit l'explication de cette anomalie apparente : [...] On ne peut donc pas espérer de perfectionner indéfiniment les instruments d'optique en faisant disparaître les aberrations géométriques [...]" - The manufacturing of the mirrors used in the telescopes is so perfect nowadays, the lenses of glasses and of microscopes are so successfully combined that the aberrations that result from the laws of geometrical optics can be almost entirely avoided. Therefore it seems that the rays coming from one luminous point should, in these instruments, converge rigorously in one single point; however, nothing of the sort, because in the best telescopes the image of a star maintains a sensible diameter. The theory which we are going to present gives an explication of this apparent anomaly: [...] One can therefore not hope to perfect the optical instruments infinitely by removing the geometrical aberrations [...].

h"La théorie précédente permet de déterminer une limite inférieure du pouvoir optique. Soient en effet deux points lumineux dont les images ont leurs centres aux points A et A'; supposons qu'il n'y ait pas de lumière sensible dans chacune de ces images au delà du premier anneau brillant: il faudra alors, pour que les deux images n'empiètent pas l'une sur l'autre, que la distance AA' soit au moins égale au double du rayon du premier anneau brillant, et, par suite, que le diamètre apparent de la droite qui joint les deux points lumineux soit au moins égal au double de la déviation du premeir anneau brillant. En désignant cette déviation par $\omega, \frac{1}{2 \omega}$ sera une limite inférieure du pouvoir optique. La déviation $\omega$ correspondant au deuxième maximum, on aura, d'après la valeur trouvée plus haut, [...] $\sin \omega=0,819 \frac{\lambda}{R} . "-$ The preceding theory [the derivation of the diffraction pattern of an annular aperture] allows a lower limit of the optical capability to be established. Let be effective two bright points whose images have the centers at $A$ and A'; suppose that there is no light detectable in any of their images beyond the first bright ring: In order not to cover one image with the other, the distance AA' must therefore be at least equal to the double of the beam of the first bright ring, and, accordingly, the apparent diameter of the perpendicular which joins the two luminous points must be at least equal to the double of the deviation of the first bright ring. If we denote this deviation with $\omega, \frac{1}{2 \omega}$ will be a lower limit of the optical capability. The deviation $\omega$ which corresponds to the second maximum, will be, according to the value found above, [...] $\sin \omega=0,819 \frac{\lambda}{R}$.

i"It would seem that the present subject, like many others, has suffered from over specialization, much that is familiar to the microscopist being almost unknown to physicists, and vice versá." j"[...], the first dark ring corresponding to one of the lines would fall on the focal point of the neighbouring one - a state of things apparently inconsistent with good definition."

k"It would certainly require a lens more than usually free from spherical aberration, and [...] achromatic [...]. It must be understood that nothing is here said against the practicability of covering a small space with lines at the rate of 3000 to the inch, a feat probably well within the powers of a good microscopic object-glass."

l'The investigation of the form and brightness of the rings or rays surrounding the image of a star as seen in a good telescope, when a diaphragm bounded by a rectilinear contour is placed upon the object-glass, $[\ldots]$ is never difficult."

m"Having ascertained about five and thirty years ago, by comparisons of the performance of several telescopes of very different apertures that the diameters of star-disks varied inversely as the diameter of the aperture, I examined with a great variety of apertures a vast number of double stars, whose distances seemed to be well determined, and not liable to rapid change, in order to ascertain the separating power of those apertures, as expressed in inches of aperture and seconds of distance. I thus determined as a constant, that a one-inch aperture would just separate a double star composed of two stars [...], if their central distance was $4^{\prime \prime} .56$; - the atmospheric circumstances being moderately favourable. Hence, the separating power of any given aperture, $a$, will be expressed by the fraction $4^{\prime \prime} .56 / a . "$

Competing interests

The author declares that he has no competing interests.

\section{Acknowledgements}

Excellent help of the librarians Bernhard Reuse and Renate Hägele of the Otto Hahn Library at the Max Planck Institute for Biophysical Chemistry, Göttingen, Germany, for obtaining literature is acknowledged. Elizabeth Carroll is thanked for careful reading of the manuscript.

Received: 4 November 2011 Accepted: 9 October 2012

Published: 1 November 2012

\section{References}

Abbe E (1873) Beiträge zur Theorie des Mikroskops und der mikroskopischen Wahrnehmung. M. Schultze's Archiv für mikroskopische Anatomie 9: 413-468

Abbe E (1880) Ueber die Grenzen der geometrischen Optik. Jenaische Zeitschrift für Naturwissenschaft. Sitzungsberichte 14:71-109

Airy GB (1835) On the diffraction of an object-glass with circular aperture. Trans Cambridge Philos Soc 5: 283-291

Airy GB (1841) On the diffraction of an annular aperture. Philos Mag Third Series 18(114): 1-10

Anderson MS (2000) Locally enhanced Raman spectroscopy with an atomic force microscope. Appl Phys Lett 76(21): 3130-3132

Ash EA, Nicholls G (1972) Super-resolution aperture scanning microscope. Nature 237(5357): 510-512 
Axelrod D (1981) Cell-substrate contacts illuminated by total internal-reflection fluorescence. J Cell Biol 89: 141-145

Bailey B, Farkas DL, Taylor DL, Lanni F (1993) Enhancement of axial resolution in fluorescence microscopy by standing-wave excitation. Nature 366(6450): 44-48

Betzig E, Patterson GH, Sougrat R, Lindwasser OW, Olenych S, Bonifacino JS, Davidson MW, Lippincott-Schwartz J, Hess HF (2006) Imaging intracellular fluorescent proteins at nanometer resolution. Science 313(5793): 1642-1645

Binnig G, Rohrer H (1983) Scanning tunneling microscopy. Surf Sci 126(1-3): 236-244

Binnig G, Quate CF, Gerber C (1986) Atomic force microscope. Phys Rev Lett 56(9): 930-933

Bossi M, Fölling J, Dyba M, Westphal V, Hell SW (2006) Breaking the diffraction resolution barrier in far-field microscopy by molecular optical bistability. New J Phys 8: 275

Brand L, Eggeling C, Zander C, Drexhage KH, Seidel CAM (1997) Single-molecule identification of Coumarin-120 by time-resolved fluorescence detection: Comparison of one- and two-photon excitation in solution. J Phys Chem A 101(24): 4313-4321

Bretschneider S, Eggeling C, Hell SW (2007) Breaking the diffraction barrier in fluorescence microscopy by optical shelving. Phys Rev Lett 98: 218103

Buxton A (1937) Note on optical resolution. Philos Mag 23(154): 440-442

Cragg GE, So PTC (2000) Lateral resolution enhancement with standing evanescent waves. Opt Lett 25: 46-48

Cortese K, Diaspro A, Tacchetti C (2009) Advanced correlative light/electron microscopy: current methods and new developments using Tokuyasu Cryosections. J Histochem Cytochem 57(12): 1103-1112

Dawes WR (1867) Catalogue of micrometrical measurements of double stars. Memoirs R Astronomical Soc 35: 137

Denk W, Strickler JH, Webb WW (1990) Two-photon laser scanning fluorescence microscopy. Science 248(4951): 73-76

den Dekker AJ, van den Bos A (1997) Resolution: a survey. J Opt Soc Am A: Opt, Image Sci, Vision 14(3): 547-557

Dickson RM, Cubitt AB, Tsien RY, Moerner WE (1997) On/off blinking and switching behaviour of single molecules of green fluorescent protein. Nature 388(6640): 355-358

di Francia TG (1952) Super-gain antennas and optical resolving power. Nuovo Cimento Supplemento al volume IX. Serie IX(3): 426-438

Dose $V$ (2009). Peer review. Europhysics Lett 86: 10000

Enderlein J (2005) Breaking the diffraction limit with dynamic saturation optical microscopy. Appl Phys Lett 87(9): 094105

Frohn JT, Knapp HF, Stemmer A (2000) True optical resolution beyond the Rayleigh limit achieved by standing wave illumination. Proc Nat Acad Sci USA 97(13): 7232-7236

Fujita K, Kobayashi M, Kawano S, Yamanaka M, Kawata S (2007) High-resolution confocal microscopy by saturated excitation of fluorescence. Phys Rev Lett 99(22) 228105

Gordon MP, Ha T, Selvin PR (2004) Single-molecule high-resolution imaging with photobleaching. Proc Nat Acad Sci USA 101: 6462-6465

Gustafsson MGL (1999) Extended resolution fluorescence microscopy. Curr Opin Struct Biol 9(5): 627-634

Gustafsson MGL (2005) Nonlinear structured-illumination microscopy: Wide-field fluorescence imaging with theoretically unlimited resolution. Proc Nat Acad Sci USA 102(37): 13081-13086

Gustafsson MGL, Agard DA, Sedat JW (1995) Sevenfold improvement of axial resolution in 3D widefield microscopy using two objective lenses. SPIE Three-Dimensional Microsc, Image Acquisition Process II. 2412:147-156

Gustafsson MGL, Agard DA, Sedat JW (1996) 3D widefield microscopy with two objective lenses: experimental verification of improved axial resolution. SPIE - Three-Dimensional Microsc, Image Acquisition Process III. 2655:62-66

Gustafsson MGL, Agard DA, Sedat JW (1999) I5 M: 3D widefield light microscopy with better than $100 \mathrm{~nm}$ axial resolution. J Microsc 195: 10-16

Hansma PK, Drake B, Marti O, Gould SAC, Prater CB (1989) The scanning ion-conductance microscope. Science 243(4891): 641-643

Hayazawa N, Inouye Y, Sekkat Z, Kawata S (2000) Metallized tip amplification of near-field Raman scattering. Opt Commun 183: 333-336
Heintzmann R, Gustafsson MGL (2009) Subdiffraction resolution in continuous samples. Nat Photonics 3: 362-364

Heintzmann R, Jovin TM, Cremer C (2002) Saturated patterned excitation microscopy - a concept for optical resolution improvement. J Opt, Soc Am A: Opt, Image Sci Vision 19(8): 1599-1609

Heisenberg W (1930) Die physikalischen Prinzipien der Quantentheorie. Hirzel, Leipzig

Hell SW (2004) Strategy for far-field optical imaging and writing without diffraction limit. Phys Lett A 326(1-2): 140-145

Hell SW (2007) Far-field optical nanoscopy. Science 316(5828): 1153-1158

Hell SW (2009) Microscopy and its focal switch. Nat Methods 6: 24-32

Hell SW, Kroug M (1995) Ground-state-depletion fluorescence microscopy: a concept for breaking the diffraction resolution limit. Appl Phys B: Lasers and Opt 60(5): 495-497

Hell S, Stelzer EHK (1992) Properties of a 4Pi confocal fluorescence microscope. J Opt, Soc Am A: Opt, Image Sci, Vision 9(12): 2159-2166

Hell SW, Wichmann J (1994) Breaking the diffraction resolution limit by stimulated emission: stimulated-emission-depletion fluorescence microscopy. Opt Lett 19(11): 780-782

Hess ST, Girirajan TPK, Mason MD (2006) Ultra-high resolution imaging by fluorescence photoactivation localization microscopy. Biophys J 91(11): 4258-4272

Hell SW, Stelzer EHK, Lindek S, Cremer C (1994) Confocal microscopy with an increased detection aperture: Type-B 4Pi confocal microscopy. Opt Lett 19(3): 222-224

Hofmann M, Eggeling C, Jakobs S, Hell SW (2005) Breaking the diffraction barrier in fluorescence microscopy at low light intensities by using reversibly photoswitchable proteins. Proc Nat Acad Sci USA 102(49): 17565-17569

Huang B, Babcock H, Zhuang X (2010) Breaking the diffraction barrier: super-resolution imaging of cells. Cell 143(7): 1047-1058

Houston WV (1927) A compound interferometer for fine structure work. Phys Rev 29(3): 478-485

Ji N, Shroff H, Zhong HN, Betzig E (2008) Advances in the speed and resolution of light microscopy. Curr Opin Neurobiol 18(6): 605-616

Kawata S, Inouye Y, Verma P (2009) Plasmonics for near-field nano-imaging and superlensing. Nat Photonics 3(7): 388-394

Klar TA, Hell SW (1999) Subdiffraction resolution in far-field fluorescence microscopy. Opt Lett 24(14): 954-956

Kirz J, Jacobsen C, Howells M (1995) Soft X-ray microscopes and their biological applications. Q Rev Biophys 28: 33-130

Kner P, Chhun BB, Griffis ER, Winoto L, Gustafsson MGL (2009) Super-resolution video microscopy of live cells by structured illumination. Nat Methods 6(5): 339-342

Lauterbach MA, Ullal C, Westphal V, Hell SW (2010) Dynamic imaging of colloidal-crystal nanostructures at 200 frames per second. Langmuir 26(18): 14400-14404

Lidke KA, Rieger B, Jovin TM, Heintzmann R (2005) Superresolution by localization of quantum dots using blinking statistics. Opt Express 13(18): 7052-7062

Lippincott-Schwartz J, Manley S (2009) Putting super-resolution fluorescence microscopy to work. Nat Methods 6: 21-23

Lu J, Min W, Conchello JA, Xie XS, Lichtman JW (2009) Super-resolution laser scanning microscopy through spatiotemporal modulation. Nano Lett 9(11): 3883-3889

Miao JW, Ishikawa T, Shen Q, Earnest T (2008) Extending X-ray crystallography to allow the imaging of noncrystalline materials, cells, and single protein complexes. Ann Rev Phys Chem 59: 387-410

Minsky M (1961) Microscopy apparatus. U.S. Patent 3013467

Müller CB, Enderlein J (2010) Image scanning microscopy. Phys Rev Lett 104(19) 198101

Müller DJ, Helenius J, Alsteens D, Dufrêne YF (2009) Force probing surfaces of living cells to molecular resolution. Nat Chem Biol 5(6): 383-390

Patterson G, Davidson M, Manley S, Lippincott-Schwartz J (2010) Superresolution imaging using single-molecule localization. Ann Rev Phys Chem 61: 345-367

Pohl DW, Denk W, Lanz M (1984) Optical stethoscopy: image recording with resolution $\lambda / 20$. Appl Phys Lett 44(7): 651-653 
Qu X, Wu D, Mets L, Scherer NF (2004) Nanometer-localized multiple single-molecule fluorescence microscopy. Proc Nat Acad Sci USA 101(31): 11298-11303

Ramsay BP, Cleveland EL, Koppius OT (1941) Criteria and the intensity-epoch slope. J Opt Soc Am 31: 26-33

Rayleigh JW (1874) On the manufacture and theory of diffraction-gratings. Philos Mag Ser 4, 47(310): 81-93

Rayleigh, JW (1896) On the theory of optical images, with special reference to the microscope. Philos Mag Ser 5 42(255): 167-195

Rice JH (2007) Beyond the diffraction limit: far-field fluorescence imaging with ultrahigh resolution. Mol Biosyst 3(11): 781-793

Rittweger E, Han KY, Irvine SE, Eggeling C, Hell SW (2009a) STED microscopy reveals crystal colour centres with nanometric resolution. Nat Photonics 3(3): 144-147

Rittweger E, Wildanger D, Hell SW (2009b) Far-field fluorescence nanoscopy of diamond color centers by ground state depletion. Europhysics Lett 86: 14001

Ruska E (1934) Über Fortschritte im Bau und in der Leistung des magnetischen Elektronenmikroskops. Zeitschrift für Physik 87: 580-602

Ruska, E (1993) The development of the electron microscope and of electron microscopy. In: Frängsmyr T, Ekspong G (eds) Nobel Lectures, Physics 1981-1990. World Scientific Publishing Ca. Pte. Ltd, Singapore, New Jersey, London, Hong Kong, pp 355-380

Rust MJ, Bates M, Zhuang XW (2006) Sub-diffraction-limit imaging by stochastic optical reconstruction microscopy (STORM). Nat Methods 3(10): 793-795

Schuster A (1904) An Introduction to the theory of optics. Edward Arnold, London

Schwentker MA, Bock H, Hofmann M, Jakobs S, Bewersdorf J, Eggeling C, Hell SW (2007) Wide-field subdiffraction RESOLFT microscopy using fluorescent protein photoswitching. Micros Res Tech 70(3): 269-280

Shao L, Isaac B, Uzawa S, Agard DA, Sedat JW, Gustafsson MGL (2008) I5S: wide-field light microscopy with 100-nm-scale resolution in three dimensions. Biophys J 94(12): 4971-4983

Sparrow CM (1916) On spectroscopic resolving power. Astrophysical J 44(2): 76-86

Stephenson JW (1877) Observations on Professor Abbe's Experiments illustrating his Theory of Microscopic Vision. Mon Microsc J 17: 82-88

Stöckle RM, Suh YD, Deckert V, Zenobi R (2000) Nanoscale chemical analysis by tip-enhanced Raman spectroscopy. Chem Phys Lett 318(1-3): 131-136

Strutt JW (1872) On the Diffraction of object-glasses. Mon Notices Astronomical Soc 33: 59-63

Synge EH (1928) A suggested method for extending microscopic resolution into the ultra-microscopic region. Philos Mag 6(35): 356-362

Temple PA (1981) Total internal-reflection microscopy: a surface inspection technique. Appl Opt 20(15): 2656-2664

Thompson RE, Larson DR, Webb WW (2002) Precise nanometer localization analysis for individual fluorescent probes. Biophys J 82(5): 2775-2783

Verdet É (1869) Leçons d' optique Physique, Volume 1. Victor Masson et fils, Paris

von Borries, B, Ruska E (1939) Magnetische Sammellinse kurzer Feldlänge. Patent Nr 680284. Deutsches Reich, Reichspatentamt

von Helmholtz H (1874) Die theoretische Grenze für die Leistungsfähigkeit der Mikroskope. Annalen der Physik und Chemie, Jubelband J. C. Poggendorff gewidmet, pp 557-584

Westphal V, Lauterbach MA, Di Nicola A, Hell SW (2007) Dynamic far-field fluorescence nanoscopy. New J Phys 9: 435

Winick KA (1986) Cramér-Rao lower bounds on the performance of charge-coupled-device optical position estimators. J Opt Soc Am A-Opt Image Sci Vision 3(11): 1809-1815

Zhuang XW (2009) Nano-imaging with STORM. Nat Photonics 3(7): 365-367

doi:10.1186/2192-2853-1-8

Cite this article as: Lauterbach: Finding, defining and breaking the diffraction barrier in microscopy - a historical perspective. Optical Nanoscopy 2012 1:8.

\section{Submit your manuscript to a SpringerOpen ${ }^{\circ}$ journal and benefit from:}

- Convenient online submission

- Rigorous peer review

- Immediate publication on acceptance

- Open access: articles freely available online

- High visibility within the field

- Retaining the copyright to your article

Submit your next manuscript at $\boldsymbol{\wedge}$ springeropen.com 